\title{
Upper extremity open fractures in hospitalized road traffic accident patients: adult versus pediatric cases
}

\author{
Guy Rubin ${ }^{1,2^{*}}$, Kobi Peleg ${ }^{3}$, Adi Givon ${ }^{3}$ and Nimrod Rozen ${ }^{1,2}$
}

\begin{abstract}
Background: Fractures in pediatrics show epidemiological characteristics which are different from fractures in adults. The objective of this study was to examine the injury profiles of open upper extremity fractures (UEFs) in all modes of injury related to road traffic accidents (RTAs) in adult and pediatric hospitalized patients.

Methods: Data on 103,465 RTA patients between 1997 and 2013 whose records were entered in a centralized country trauma database were reviewed. Data on open UEFs related to mode of injury (car, motorcycle, bicycle, and pedestrian) was compared between adult (18+ years) and pediatric (0-17 years) RTA patients.

Results: Of 103,465 RTA cases, 17,263 (16.7\%) had UEFs. Of 73,087 adults, 13,237 (18.1\%) included UEFs and of 30,378 pediatric cases, $4026(13.2 \%)$ included UEFs ( $p<0.0001)$. Of 17,263 cases with UEFs, we reviewed 22,132 fractures with $2,743(12.4 \%)$ open fractures. Adults had a greater risk for open fractures $(2221,13 \%)$ than the pediatric cases $(522,10.3 \%)(p<0.0001)$. Overall, of a total of 22,132 UEFs, most of the fractures were in the radius $(22.8 \%)$, humerus (20.3\%), clavicle (17.5\%), and ulna (15.4\%). The adult pedestrian group had a significantly higher risk for open UEFs than the pediatric group (11 vs $8 \%, p=0.0012$ ).

Conclusions: This study demonstrates the difference between adult and pediatric open fractures in hospitalized RTAs. We showed that adults had a greater risk for open UEFs compared to children, and the adult pedestrian group particularly had a significantly higher risk for open UEFs than the pediatric group.
\end{abstract}

Keywords: Adult, Bicycle, Car, Epidemiology, Open fracture, Motorcycle, Pedestrian, Pediatric, Road traffic accident, Upper extremity

\section{Background}

Fractures in children show epidemiological characteristics which are different from fractures in adults. The epidemiology of adult and pediatric fractures was studied in Edinburgh, Scotland, where it was found that the incidence of fractures in children was almost twice that of fractures in adults. Equal numbers of male and female adults were affected, but there is a strong male predominance in pediatric cases. More adults present with multiple and open fractures. Another difference is that children present mainly with upper limb fractures and have relatively few lower limb fractures $[1,2]$.

\footnotetext{
* Correspondence: guytalr@bezeqint.net

'Orthopaedic Department, Emek Medical Center, Afula, Israel

${ }^{2}$ Faculty of Medicine, Technion, Haifa, Israel

Full list of author information is available at the end of the article
}

In recent studies on upper extremity fractures (UEFs) in road traffic accident (RTA) hospitalized adult and pediatric patients $[3,4]$, we found that the fracture rate in children is less than that in adults. Of the total number of pedestrian accidents, about $22 \%$ of the children sustained fractures, while $40 \%$ of the adults sustained fractures in the same type of accident. The rate of UEFs in the pediatric population was $13.2 \%$ compared to $19.9 \%$ in the adult group. Multiple UEFs were similar between the groups $(23 \%$ in the pediatric group and $22 \%$ in the adult group). Associated injuries to UEFs were found in about half of our group (56\%) but in most of our adult population group (76\%). The most frequent UEFs in our pediatric group were similar to our 
Table 1 Total number of patients and distribution of RTA type among UEF patients

\begin{tabular}{llllll}
\hline & Car & Motorcycle & Bicycle & Pedestrian & Total \\
\hline Total patients & 47,176 & 13,087 & 16,319 & 26,883 & 103,465 \\
$\begin{array}{l}\text { No. 0-17 } \\
\text { patients }\end{array}$ & 6,842 & 1,192 & 10,350 & 11,994 & 30,378 \\
$\begin{array}{l}\text { No. 18+ } \\
\text { patients }\end{array}$ & 40,334 & 11,895 & 5,969 & 14,889 & 73,087 \\
$\begin{array}{l}\text { No. (\%) UEFs } \\
\text { patients }\end{array}$ & $6,459(37)$ & $3,463(20)$ & $3,389(20)$ & $3,952(23)$ & 17,263 \\
$\begin{array}{l}\text { No. (\%) UEFs } \\
\text { 0-17 }\end{array}$ & $803(20)$ & $217(6)$ & $1,906(47)$ & $1,100(27)$ & 4,026 \\
$\begin{array}{l}\text { No. (\%) UEFs } \\
18+\end{array}$ & $5,656(43)$ & $3,246(24)$ & $1,483(11)$ & $2,852(22)$ & 13,237 \\
\hline
\end{tabular}

adult group and included the forearm, humerus, and clavicle.

The aim of this study was to identify the epidemiology of RTA open UEFs and to define any commonly occurring patterns. This study focused on all modes of injury related to RTAs (car, motorcycle, bicycle, pedestrian), regarding fracture pattern and age difference.

\section{Methods}

RTA patients (car, motorcycle, bicycle, and pedestrian) in Israel between 1997 and 2013 were reviewed. Data were obtained from the Israel National Trauma Registry (ITR), maintained by Israel's National Center for Trauma and Emergency Medicine Research at the Gertner Institute for Epidemiology and Health Policy Research. The ITR does not collect data on individuals who were dead at the scene or upon arrival at the hospital, nor does it include patients discharged to home from the Emergency Department. Data are recorded by trained medical registrars at each hospital, and electronic files are transferred to the ITR. During the study period, the ITR included trauma patients admitted to all six level I trauma centers and up to 13 regional trauma centers in Israel.

Medical diagnosis classifications were from the International Classification of Diseases, Ninth Revision, Clinical Modification.

Data included diagnosis of open UEF and type of UEF among different RTA modes. These characteristics were compared between adult (18+ years) and pediatric (0-17 years) RTA patients.

Statistical analysis was performed using SAS statistical software version 9.2 (SAS, Cary, NC). Statistical tests performed included the chi-square test and binomial proportions test. A $p$ value less than 0.05 was considered as statistically significant.

Ethical approval was not necessary since the data was collected from a national data registry without patient details.

\section{Source of funding}

There was no external funding source.

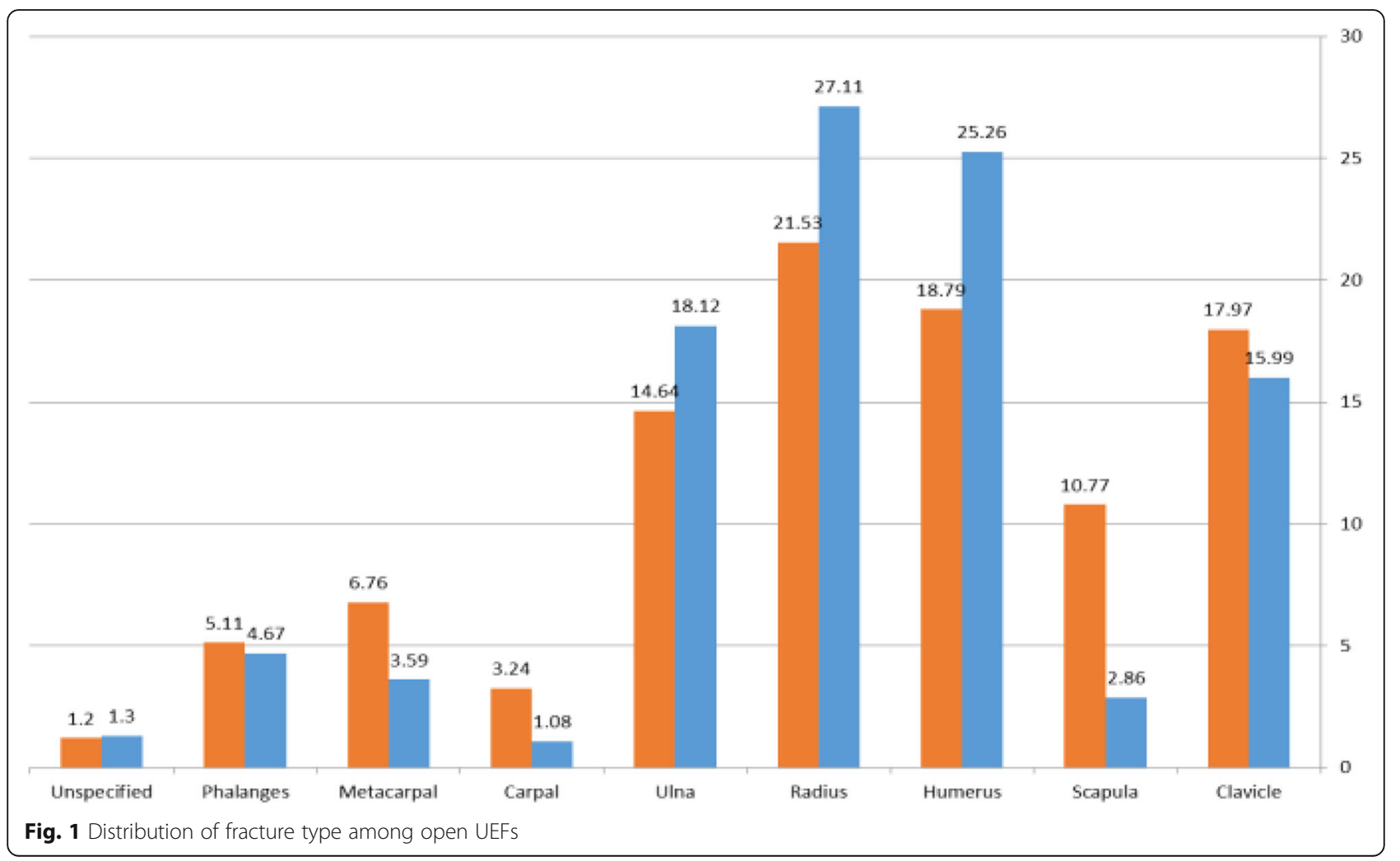




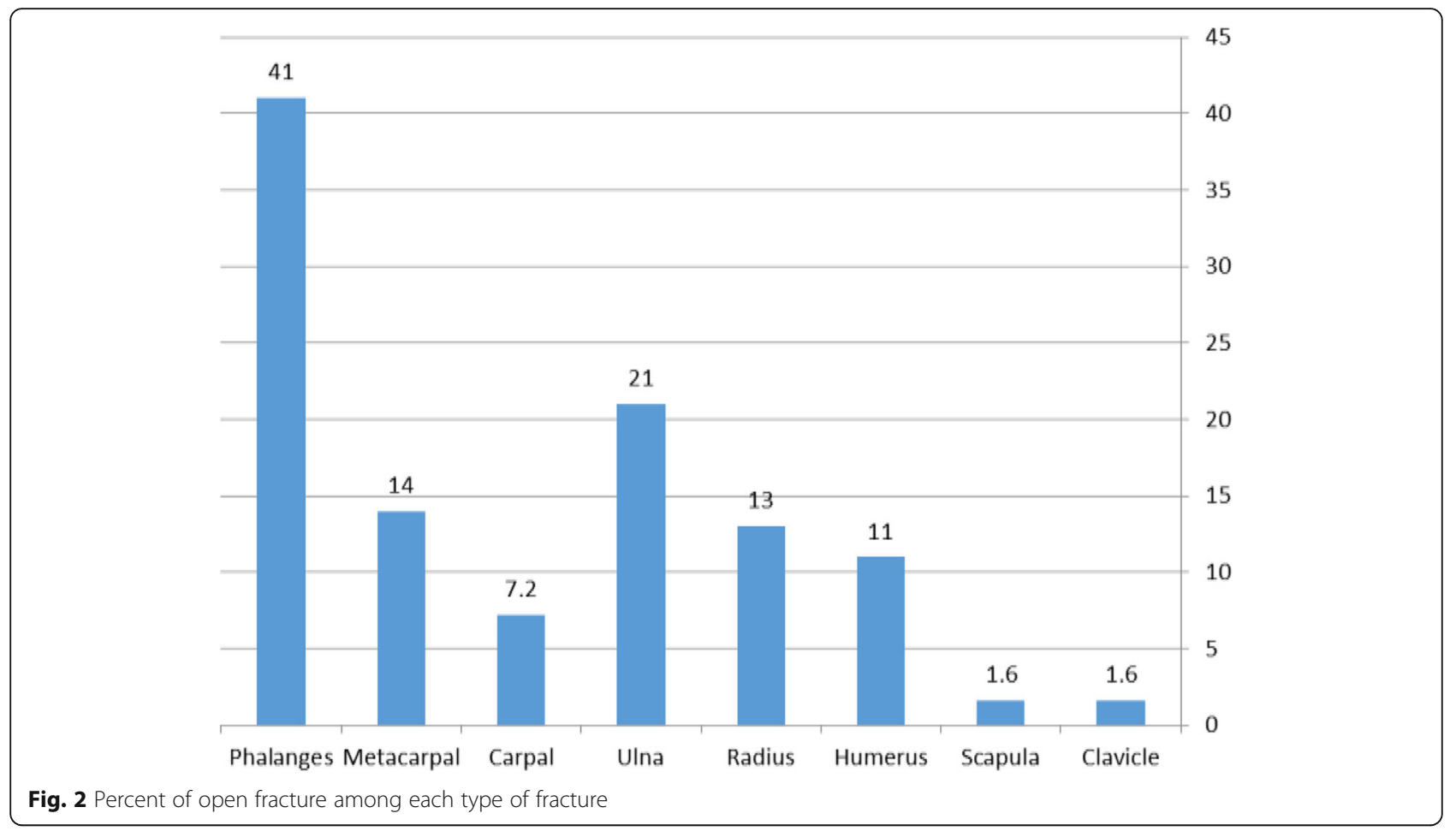

\section{Results}

Of 103,465 RTA cases recorded in the ITR in 1997-2013, 17,263 (16.7\%) had UEFs. Of 73,087 adults, 13,237 (18.1\%) included UEFs and of 30,378 pediatric cases, 4026 (13.2\%) included UEFs $(p<0.0001)$ (Table 1$)$.

Of 17,263 cases with UEFs we reviewed, there were 22,132 fractures with 2, 743 (12.4\%) open fractures. Adults had a greater risk for open fractures (2221, 13\%) than the children $(522,10.3 \%)(p<0.0001)$.

\section{Fracture type}

Overall, of a total of 22,132 UEFs, most of the fractures were in the radius (22.8\%), humerus (20.3\%), clavicle (17.5\%), and ulna (15.4\%). The adult group had a similar distribution of fracture type, but the pediatric group had more ulna fractures than clavicle fractures (Fig. 1).

The percent of open fracture according to fracture type demonstrated that the risk for open fractures in the phalanges was $41 \%$, followed by the ulna (21\%), metacarpals (14\%), and the radius (13\%) (Fig. 2).

\section{Mode of injury}

Of 17,263 cases with UEFs we reviewed, 6459 (37\%) were in car occupants, 3463 (20\%) in motorcycle riders, 3389 (20\%) in bicycle riders, and $3952(23 \%)$ in pedestrians.

Of 22,132 UEFs we reviewed, there were 2743 (12.4\%) open fractures with 1198 (14\%) in car occupants, 589 (13\%) in motorcycle riders, $473(11 \%)$ in bicycle riders, and $483(10 \%)$ in pedestrians. The adult pedestrian group had a significantly higher risk for open UEFs than the pediatric group (11 vs $8 \%, p=0.0012$ ) (Table 2).

The risk for each open fracture according to mode of injury and age group is presented in Table 3. In car occupants, the most frequent open fractures in adults were ulna (25\%), radius $(24 \%)$, and humerus (21\%), compared to pediatrics with radius $(26 \%)$, phalanges $(25 \%)$, and ulna (23\%). In motorcycle riders, the most frequent open fractures in adults were ulna (31\%), radius (27\%), and phalanges (17\%), compared to pediatrics with radius (35\%), ulna (31\%), and phalanges (23\%). In bicycle riders, the most open fractures in adults were ulna (32\%), radius (25\%), and phalanges (15\%), compared to pediatrics with radius (30\%), ulna (28\%), and phalanges (20\%). In pedestrians, the most frequent open fractures in adults were humerus (28\%), ulna (21\%), and radius (18\%), compared to pediatrics with humerus (33\%), radius (19\%), phalanges (18\%), and ulna (16\%).

Table 2 Percent of patients with UEF from total patients in each type of RTA

\begin{tabular}{llllll}
\hline & Car & Motorcycle & Bicycle & Pedestrian & Total \\
\hline Total UEFs & 8,339 & 4,646 & 4,324 & 4,823 & 22,132 \\
$\begin{array}{l}\text { No. (\%) open } \\
\text { UEFs }\end{array}$ & $1,198(14)$ & $589(13)$ & $473(11)$ & $483(10)$ & $2,743(12)$ \\
$\begin{array}{l}\text { No. (\%) 0-17 } \\
\text { open UEFs }\end{array}$ & $138(13.5)$ & $26(9)$ & $260(10.5)$ & $98(8)$ & $522(10)$ \\
$\begin{array}{l}\text { No. (\%) 18+ } \\
\text { open UEFs }\end{array}$ & 1,060 & $563(13)$ & $213(12)$ & $385(11)$ & $2,221(13)$ \\
$\begin{array}{l}p \text { value 0-17 } \\
\text { vs 18+ }\end{array}$ & 0.4237 & 0.0656 & 0.2182 & 0.0012 & \\
\hline
\end{tabular}




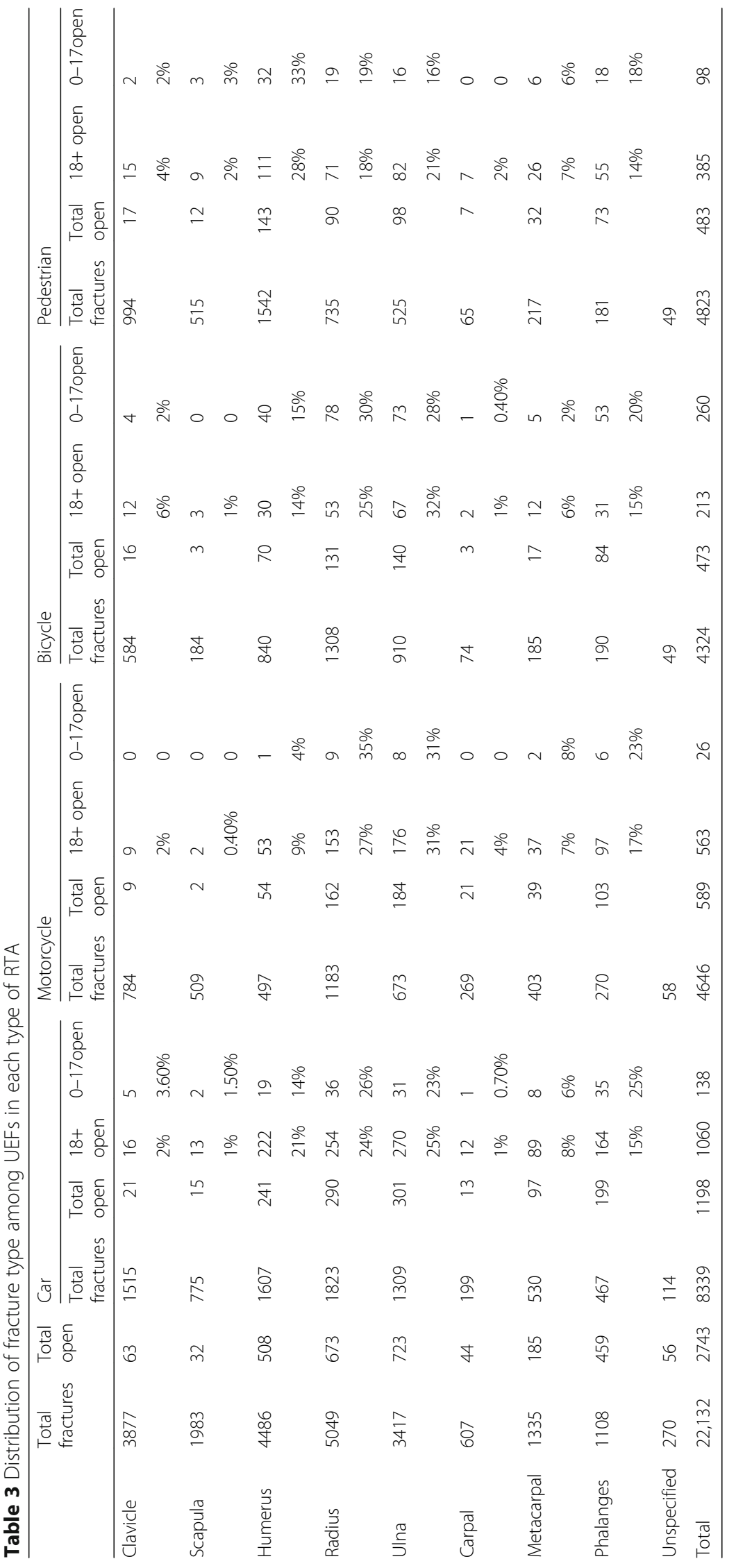




\section{Discussion}

Open fractures are relatively uncommon and can be complicated with soft tissue damage and compartment syndrome [5]. A study on fracture epidemiology in Edinburgh, Scotland, in 2007-2008 indicated that 59\% of the fractures were in the upper limb and only $2.6 \%$ of 5271 fractures were open [1]. Court-Brown et al. analyzed all inpatient and outpatient open fractures in a defined adult ( $>15$ years) population over a 15-year period. They treated 2386 open fractures in 2206 patients, giving an incidence of 30.7/105/year [6]. Rennie et al. studied the epidemiology of fractures in children $(<16)$ presenting to hospitals in Edinburgh, Scotland, in 2000. They found 2198 fractures in 2168 patients. The overall incidence was 20.2 fractures/1000/year. A review of fracture location showed that $82.2 \%$ were in the upper limb, $17.3 \%$ were in the lower limb, and $0.5 \%$ were in the pelvis or spine. Only $0.7 \%$ of fractures were open [2]. Our study showed that open UEFs as a result of RTAs are common in patients admitted to the hospital, with up to $12 \%$ of the fractures. We demonstrated that adults had a greater risk for open UEFs as compared to children (13 vs $10 \%, p<0.0001$ ).

The number of open fractures according to mode of injury demonstrated up to $14 \%$ in car occupants. Richter et al. demonstrated that a total of $16 \%$ of all cases of front seat car occupants were open injuries [7]. Court-Brown et al. found that only $22.3 \%$ of adult open fractures were caused by RTAs or falls from a height [5]. Of the total number of pedestrians involved in vehicle accidents, about $22 \%$ of the children sustained fractures, while $40 \%$ of the adults sustained fractures in the same type of accident. This has been attributed to the fact that children are more likely to "bounce" when hit [8]. We found that the adult pedestrian group had a significantly higher risk for open UEFs than the pediatric group ( 11 vs $8 \%, p=0.0012$ ).

The highest prevalence for an open UEF according to type of bone in the adult general population occurs in the phalanges followed by the forearm [1]. This data has not been studied in the pediatric population. In our study, we demonstrated that the adult group had a similar distribution of fracture type but the pediatric group had more ulna fractures than clavicle fractures.

The limitations of this study are its retrospective nature and the data concerning only hospitalized patients with no data concerning close fractures, other body parts fractures, open fracture classification, or other soft tissue complications. However, the large cohort study and the recommendation for intravenous antibiotic treatment to open fracture inpatients [9] make this study a valuable source of information on the epidemiology of UEFs in adult and pediatric patients.

\section{Conclusions}

This study demonstrates the difference between adult and pediatric open fractures in hospitalized RTAs. We showed that adults had a greater risk for open UEFs compared to children, and the adult pedestrian group particularly had a significantly higher risk for open UEFs than the pediatric group.

\section{Abbreviations}

RTAs: Road traffic accidents; UEFs: Upper extremity fractures

\section{Acknowledgements}

None

\section{Funding}

No funding.

Availability of data and materials

Data is available in Emek Medical Center.

\section{Authors' contributions}

GR contributed to the conception and design, acquisition of data, analysis, and interpretation of data, drafting the article, and final approval. KP contributed to the analysis and interpretation of data, revising the article, and final approval. AG contributed to the conception and design, acquisition of data, revising the article, and final approval. NR contributed to the conception and design, acquisition of data, revising the article, and final approval. All authors read and approved the final manuscript.

Consent for publication

Not applicable.

\section{Competing interests}

The authors declare that they have no competing interests.

\section{Publisher's Note}

Springer Nature remains neutral with regard to jurisdictional claims in published maps and institutional affiliations.

\section{Author details}

${ }^{1}$ Orthopaedic Department, Emek Medical Center, Afula, Israel. ${ }^{2}$ Faculty of Medicine, Technion, Haifa, Israel. ${ }^{3}$ National Center for Trauma \& Emergency Medicine Research, Gertner Institute for Epidemiology and Health Policy Research, Sheba Medical Center, Tel Hashomer, Israel.

Received: 2 March 2017 Accepted: 16 October 2017

Published online: 24 October 2017

References

1. Court-Brown CM, Aitken SA, Forward D, OToole RV. The epidemiology of fractures. In: Rockwood CA, Green DP, Bucholz RW, editors. Rockwood and Green's fractures in adults. 7th ed. Philadelphia: Wolters Kluwer Health/ Lippincott Williams \& Wilkins; 2010. p. 53-84.

2. Rennie L, Court-Brown CM, Mok JY, Beattie TF. The epidemiology of fractures in children. Injury. 2007;38(8):913-22.

3. Rubin G, Peleg K, Givon A, Rozen N. Upper extremity fractures among hospitalized road traffic accident adults. Am J Emerg Med. 2015;33(2):250-3.

4. Rubin G, Peleg K, Givon A, Rozen N. Upper extremity fractures among hospitalized pediatric road traffic accident victims. Am J Emerg Med. 2015;33(5):667-70.

5. Via AG, Oliva F, Spoliti M, Maffulli N. Acute compartment syndrome. Muscles Ligaments Tendons J. 2015;5(1):18-22.

6. Court-Brown CM, Bugler KE, Clement ND, Duckworth AD, McQueen MM. The epidemiology of open fractures in adults. A 15-year review. Injury. 2012;43(6):891-7.

7. Richter M, Otte D, Jahanyar K, Blauth M. Upper extremity fractures in restrained front-seat occupants. J Trauma. 2000;48(5):907-12.

8. Derlet RW, Silva J Jr, Holcroft J. Pedestrian accidents: adult and pediatric injuries. J Emerg Med. 1989;7(1):5-8.

9. Hauser CJ, Adams CA Jr, Eachempati SR. Surgical infection society guideline: prophylactic antibiotic use in open fractures: an evidence-based guideline. Surg Infect. 2006;7(4):379-405. 